\title{
ESCRITORAS DE LAS MINORÍAS ÉTNICAS EN CANADÁ
}

M. TEREsA GiBert-MACEDA

UNED

Las mujeres ocupan un lugar preferente en el canon literario del Canadá anglófono. Aunque casi todas ellas pertenecen a la mayoría «WASP» (=«White Anglo-Saxon Protestant», de raza blanca, raíces culturales anglosajonas y religión protestante), algunas escritoras pertenecientes a las minorías étnicas del país se van abriendo paso con obras que, además de interesar al público general, atraen la atención de la crítica especializada. Sin necesidad de establecer unos sistemas de valores diferentes de los que estamos habituados a aplicar, es decir, incluso manteniendo los mismos criterios con los que juzgamos los textos ya integrados en el canon, es posible apreciar la riqueza de estas recientes aportaciones a la todavía joven literatura canadiense.

Por nuestra parte, resultaría vano y arrogante el intento de interpretar estas obras «desde dentro», basándose en la absurda pretensión colonialista e imperialista según la cual los investigadores occidentales serían capaces no sólo de comprender perfectamente cualquier civilización - por extraña que para ellos fuera-, sino también de integrarse o separarse de ella en función de sus gustos personales o de sus objetivos científicos. Más sensato parece el acercarse a esta literatura aceptando desde un principio las limitaciones inhe- 
rentes a una visión necesariamente parcial y condicionada por la formación que hemos recibido'.

Aun siendo conscientes de que el deseo de generalizar acerca de tal variedad de modelos implica el riesgo de ofrecer una visión simplista de realidades complejas, es apasionante reflexionar sobre el significado que para nosotros tiene la apertura de mundos imaginativos nuevos. La lectura de estas obras, al mostrarnos distintas formas de percibir la existencia humana expresadas desde diversas perspectivas, nos ayuda a superar algunas de las deficiencias que restringen nuestros particulares puntos de vista. En definitiva, tales obras nos permiten comprender mejor nuestra propia sociedad europea que, como la canadiense, tiende hacia el multiculturalismo y la pluralidad racial.

Las mujeres de las minorías étnicas en Canadá suelen escribir en inglés, la más extendida de las dos lenguas oficiales, a pesar de que en ocasiones ésta constituya su segunda lengua, aprendida al iniciar los estudios primarios o al emigrar durante la infancia o la adolescencia. La adopción de la lengua mayoritaria del país les permite acceder a los circuitos de publicación y les ofrece la esperanza del éxito editorial, difícil para cualquier canadiense en un mercado incapaz de competir económicamente con la poderosa industria estadounidense. Sin embargo, aunque la mayor parte de cada narración esté redactada en inglés, la lengua materna de las autoras suele hacerse presente mediante diversos recursos: inclusión de elementos típicos del habla coloquial de su etnia, aparición de rasgos fonéticos característicos, traducción literal de expresiones idiomáticas, empleo de vocablos sin equivalencia exacta en inglés (por ejemplo, el léxico del vestido, la alimentación o los objetos de uso doméstico inexistentes en la cultura anglosajona), etc. Considerando que los lectores anglófonos pueden desconocer esa lengua minoritaria, siempre se utiliza algún procedimiento con el fin de que los términos extranjeros resulten inteligibles para todos. En ocasiones, el personaje que habla en su lengua repite a continuación en inglés lo que acaba de decir; a veces, otro personaje, o el propio narrador, efectúa la correspondiente traducción de la palabra o frase, generalmente breve. Pero

${ }^{1}$ Cfr. \&It is imperative that we look more closely at Native literature and judge it not within a European cultural paradigm but from the points of view of the culture from which it springsm. AGNEs Grant, «Contemporary Native Women's Voices in Literature», en W.H. NEW (ed.), Native Writers and Canadian Writing, Vancouver, UBC Press, 1990, p. 126. Este tipo de afirmaciones, tan bienintencionadas como perjudiciales para los propios nativos, se han convertido en un lugar común en los estudios sobre las literaturas que tradicionalmente han quedado relegadas. La aceptación rigurosa de tales principios nos obligaría a tratar únicamente lo conocido de manera inmediata e impediría analizar fenómenos alejados en el espacio o en el tiempo. Llevando la teoría al extremo, sólo podríamos estudiar y apreciar las obras de los autores de nuestro mismo país, sexo, raza, clase social, época, etc. 
también existen otras formas de hacerse entender sin recurrir a la traducción, pues los significados se infieren a partir del contexto. Por ejemplo, si el narrador explica cómo está rezando una griega a la Virgen, el lector no encuentra dificultad alguna para identificar a la Panagia en la oración de la mujer; también resulta fácil comprender que los niños llaman giagía a su abuela, con lo cual se captará la referencia cada vez que aparezca el vocablo en lo sucesivo.

La aparición de elementos de la lengua extranjera a través del texto inglés tiene como finalidad principal mostrar el grado de integración de los personajes en la sociedad canadiense. Los miembros más ancianos de la comunidad, y también algunos jóvenes que han emigrado recientemente, son los que utilizan su lengua materna con mayor frecuencia, poniendo de manifiesto un número más elevado de interferencias lingüísticas cuando hablan en inglés. Quienes pertenecen a la segunda o tercera generación de familias inmigrantes se expresan en inglés con fluidez y sólo emplean la otra lengua esporádicamente, por ejemplo al dirigirse a sus familiares con apelativos que subrayan la afectividad o en momentos de gran intensidad emocional. Asimismo, la mención de las koulourákia al referirse a las típicas rosquillas griegas, o a los contadini en un contexto italiano, ejerce una función decorativa que contribuye a la creación de un determinado ambiente.

Junto a los aspectos más anecdóticos e incluso humorísticos del bilingüismo y la diglosia, también aparecen otros de carácter conflictivo suscitados por la colisión entre dos lenguas dentro de una comunidad étnica, una familia, o incluso dentro de un mismo individuo. Así, los deseos de asimilación dentro del nuevo entorno contrastan con los de apego a las tradiciones cuando los familiares se enfrentan a la decisión de elegir el nombre de los hijos nacidos en Canadá. Los hermanos del recién nacido suelen manifestar opiniones contrarias a las de los abuelos, mientras que los padres procuran buscar una solución de compromiso optando por nombres que no resulten ridículos o demasiado difíciles de pronunciar en alguno de los dos ámbitos. Por ejemplo, en Itsuka unas niñas japonesas se oponen a que su hermanita reciba el nombre de Kazuko y, aunque hubieran querido llamarla Anne como a la protagonista de Anne of Green Gables, se conforman con Anna porque los inmigrantes japoneses recientes dirían «Annu» en vez de "Anne» ${ }^{2}$. En Honour the Sun, una pequeña india se avergüenza de que en casa la conozcan bajo el apodo de «The Owl» («La Lechuza») ${ }^{3}$. En cambio, cuando Alice French publica los recuerdos de su niñez, elige el título de My Name Is Masak, reafirmando así con orgullo su nombre

2 JoY KOGAWA, Itsuka, Toronto, Viking, 1992, pp. $35-9$.

3 Ruby SlipPERJack, Honour the Sun, Winnipeg, Pemmican Publications, 1987. 
esquimal, perdido durante los años de internado y recuperado al volver con su familia ${ }^{4}$. Igualmente, el título de Geniesh: An Indian Girlhood incluye el nombre con el que su autora - Jane Willis - era conocida entre los suyos pues, según explica ella misma, Geniesh significa «Little Janie». De manera general podríamos afirmar que la actitud positiva o negativa hacia el nombre propio es uno de los indicadores más claros de los deseos de asimilación o de la resistencia ante ella.

A fin de evitar los inconvenientes que pudiera acarrear el hacer patente su origen, algunos personajes modifican sus propios nombres o adoptan otros nuevos. Un nombre extranjero, según comenta la escritora de raíces turcas Yeshim Ternar, constituye una importante traba para la integración ${ }^{6}$. Ella cuenta cómo, al poco tiempo de naturalizarse como ciudadana canadiense, acudió a votar y, cuando con gran amabilidad le preguntaron de qué nacionalidad era su nombre, respondio: «canadiense». El incidente pone de relieve cómo, aun en el caso de ser tratados con afecto, los inmigrantes reconocen no ser plenamente aceptados, aunque sean de raza blanca y hablen inglés o francés sin acento extranjero.

Ahora bien, los problemas lingüísticos más agudos son los ocasionados por el desconocimiento o el deficiente dominio del inglés por parte de las personas de avanzada edad, en especial las mujeres, cuyos sentimientos de marginación y soledad se acentúan por tal motivo. Así, Eleni, la protagonista del relato de Katherine Vlassie «A Proper Goodbye», se lamenta de que su marido hablara siempre en inglés con sus hijos, nacidos ya en Canadá, y que, en consecuencia, ella quedara excluída junto con su hija de las conversaciones entre los hombres ${ }^{7}$. Eleni también recuerda con tristeza las excusas (una jaqueca o la falta de gafas) a las que tenía que recurrir para disimular su ignorancia ante sus nietos cuando le pedían que les leyera cuentos en inglés ${ }^{8}$. La protagonista turca del relato de Yeshim Ternar «Ajax Là Bas» es una maestra que se ha desplaza-

4 «Then she introduced me to the other girls by my Christian name - Alice. My Eskimo name was not mentioned and I did not hear my name Masak again until I went home». ALICE French, My Name Is Masak, Winnipeg, Penguis Publishers, 1976.

5 «Everyone, however, called me Geniesh, which means Little Janie». JANE WILLIS, Geniesh: An Indian Girlhood, Toronto, New Press, 1973.

6 Entrevista de Yeshim Yashar Ternar con Linda Leith, en Linda Hutcheon \& Marion Richmond (eds.), Other Solitudes. Canadian Multicultural Fictions, Toronto, Oxford University Press, 1990, p. 328.

7 Katherine Vlassie, «A Proper Goodbyew, repr. en Linda Hutcheon \& Marion Richmond (eds.), Other Solitudes. Canadian Multicultural Fictions, Toronto, Oxford University Press, 1990, pp. 102-13.

8 Op. cit., cfr. p. 111. 
do a Montreal para aprender inglés y francés ${ }^{9}$. Sin embargo, la joven Saliha está muy lejos de alcanzar su objetivo, debido a que su trabajo como limpiadora doméstica no le ofrece oportunidad alguna de comunicarse con los demás.

Las narraciones de las escritoras pertenecientes a las minorías étnicas suelen reflejar las experiencias inmediatas de sus autoras, con un énfasis particular sobre la vida cotidiana de ellas mismas o de otros miembros de su comunidad. Los temas recurrentes son: la experiencia de la inmigración, el «choque cultural», el desarraigo, los recuerdos (a veces ambivalentes) en torno al país de origen, la discriminación (como mujeres y como miembros de una minoría étnica), las relaciones internas (dentro de la comunidad minoritaria) y externas (con otras minorías marginadas y con la mayoría dominante).

Aunque casi todas estas obras se sitúan en el presente, también aparece el pasado más o menos reciente cuando tiene relevancia para explicar la situación actual. En este sentido ofrecen un interés particular Obasan (1981) e Itsuka (1992), dos novelas a través de las cuales Joy Kogawa pone de manifiesto el injusto tratamiento que unos 22.000 canadienses de origen japonés sufrieron durante y después de la Segunda Guerra Mundial. Bajo la sospecha de que pudieran colaborar con el enemigo, el gobierno canadiense de aquella época les obligó a abandonar sus casas y empleos, confiscó sus propiedades y utilizó los fondos derivados de la venta para concentrar a las familias, primero en campos para después realojarlas -dividiéndolas arbitrariamente- en zonas del interior, donde los habitantes las recibieron con hostilidad. Estas medidas de tipo coercitivo, en vigor desde 1942 hasta 1949, tuvieron como resultado la dispersión de las comunidades que a lo largo de los años se habían ido instalando pacíficamente en la costa oeste de Canadá. Kogawa se basa en los hechos históricos vividos por ella misma para escribir dos novelas que, a pesar de sus abundantes elementos de carácter autobiográfico, no constituyen una autobiografía en sentido estricto, sino ejemplos de lo que Linda Hutcheon denomina «metaficción historiográfica» 10 .

La protagonista, Naomi Nakane, presenta muchos rasgos comunes con la autora, Joy Kogawa. Ambas nacieron en Vancouver con sólo un año de dife-

9 Yeshim Ternar, «Ajax Là Bas», repr. en Linda Hutcheon \& Marion Richmond (eds.), Other Solitudes. Canadian Multicultural Fictions, Toronto, Oxford University Press, 1990, pp. 321-8.

10. «The form I would like to call «historiographic metafiction» - fiction that is intensely, selfreflexively art, but is also grounded in historical, social and political realities». LINDA HUTCHEON, The Canadian Postmodern. A Study of Contemporary English Canadian Fiction, Toronto, Oxford University Press, 1988, p. 13. 
rencia (1936 y 1935 respectivamente) formando parte de la tercera generación de canadienses de origen japonés: los sansei ${ }^{11}$. En 1942 la familia de Kogawa fue evacuada a Slocan (British Columbia), donde vivió hasta que en 1945 la desplazaron a Coaldale (Alberta). Idéntica suerte padeció Naomi Nakane, trasladada en 1942 de Vancouver a Slocan, y en 1945 a Granton, pueblo situado a 70 millas de Coaldale. Otros paralelismos entre la autora y su personaje incluyen la religión cristiana, los estudios de Magisterio y, sobre todo, el compromiso político que les induce a participar en el movimiento a favor de la compensación legal de los daños sufridos. La publicación de Obasan en 1981 contribuyó muy eficazmente al éxito de la campaña, gracias a la cual el gobierno de Canadá aprobó en 1988 un reconocimiento oficial de las injusticias cometidas contra un grupo de sus leales ciudadanos. El texto de dicho reconocimiento figura impreso al final de Itsuka y cierra así con una nota de esperanza uno de los episodios más dolorosos de la historia de Canadá.

El hecho de que ambas novelas posean un abundante contenido político no las convierte en meros instrumentos de propaganda al servicio de una causa. Ambas, en especial la primera, están admirablemente construídas, con una caracterización perfecta y un lenguaje muy sugerente, lleno de imágenes bellísimas. Son, en definitiva, fruto de una escritora que antes de ser novelista fue poeta.

La narradora alterna su experiencia presente de persona adulta con los recuerdos de su pasado, cuando contemplaba con ojos infantiles unas escenas que quedaron grabadas en su memoria, pero que la niña inocente y sensible no sabía interpretar. Ahora sí comprende en todas sus dimensiones la magnitud de la tragedia y reflexiona sobre sus diferentes aspectos, ayudada por cartas, diarios, recortes de periódicos y otros documentos de la época. Las dos tías de Naomi, que ha perdido a su madre en el bombardeo de Nagasaki, representan dos reacciones opuestas que caben ante una situación límite de este tipo. Obasan, cuyo nombre da título a la primera novela, con su actitud silenciosa y resignada simboliza la paciencia ante las adversidades. Por el contrario, la tía Emily, de temperamento apasionado y combativo, se convierte en una militante que lucha enérgicamente por defender a los suyos. Naomi consigue mantener una posición de equilibrio entre sus dos tías, sostenida por el amor que ambas le profesan, lo cual facilita su camino hacia la reconciliación.

Es probable que Obasan se convierta en la novela emblemática de las escritoras pertenecientes a las minorías étnicas en Canadá, ya que ejemplifica sus características distintivas y las eleva a un notable grado de calidad literaria. Al

11 Joy Kogawa, Obasan, London, Penguin, 1981, p. 7. 
mismo tiempo, esta obra ejerce un fuerte impacto emocional sobre los lectores, por alejados que crean estar de esa realidad en el espacio o en el tiempo. Esencialmente, se abordan los problemas sociales e individuales causados por la alienación de las minorías que, en numerosos lugares y momentos de la historia universal, han dado lugar a holocaustos similares en tiempos de crisis. Por ello, aunque la novela esté enraizada en una situación concreta, plantea cuestiones de interés más amplio y permanente, pues la alteridad es un fenómeno que existe y siempre ha existido en todas las naciones.

Joy Kogawa nos recuerda que la alteridad existe incluso dentro del grupo de los marginados, debido a que ellos mismos a su vez establecen formas de marginación con respecto a algunos de sus miembros. Así, cuando se extiende la noticia de que el padre de Naomi tiene tuberculosis, la propia niña se ve rechazada por sus amigas Yuki y Reiko. Las pequeñas, aleccionadas por sus madres, no sólo se apartan por temor al contagio, sino que además fantasean sobre las causas de la enfermedad y aprovechan la ocasión para humillar a Naomi (Obasan, pp. 165-6). Con esta clase de percepciones, Kogawa demuestra que ha superado la visión simplista que con frecuencia se supone es patrimonio común de los escritores pertenecientes a las minorías étnicas. En efecto, está muy extendida la creencia de que tales escritores adoptan ante la vida una actitud maniquea que les induce a ver únicamente la bondad de su etnia, sin capacidad para la autocrítica. Las obras de Joy Kogawa, al desplegar tan ricos matices, ponen de relieve lo erróneo del prejuicio. La caracterización del hermano de Naomi evidencia cómo, dentro de los grupos de marginados, también hay seres egoistas y desagradecidos. En Canadá, como en cualquier otro país del mundo, se dan cita todo género de personas: «We come from Canada, this land that is like every land, filled with the wise, the fearful, the compassionate, the corrupt» (Obasan, 226).

Es importante reseñar que los ejemplos citados en la narrativa de Kogawa no representan casos aislados. «Dancing», el relato de Neil Bissoondath, originario de Trinidad, deja bien patente que el racismo no es un sentimiento exclusivo de los blancos y que, cuando los inmigrantes incurren en un comportamiento reprobable, son, hasta cierto punto, culpables de su propia marginación. Otro escritor negro de Barbados, Austin Clarke, insiste en el sentido de responsabilidad que cada inmigrante debe asumir con respecto a su propia situación. Consecuentemente, al comentar el relato «Canadian Experience», Clarke observa que el protagonista es el responsable último de su trágico fin ${ }^{12}$.

12 Entrevista de Austin Clarke con Marion Richmond, en LINDA Hutcheon \& MARION Richmond (eds.), Other Solitudes. Canadian Multicultural Fictions, Toronto, Oxford University Press, 1990, pp. 67-8. 
Es digno de elogio el paulatino incremento de la capacidad de autocrítica conducente a superar las estériles actitudes pasivas y compasivas hacia uno mismo. Muchos escritores y escritoras actuales son conscientes de que la ruptura de los estereotipos de opresores y víctimas es el primer paso para la liberación. Precisamente ha sido la cultura dominante la principal forjadora de tales estereotipos que han venido repitiéndose en la literatura norteamericana. Quizás el más claro ejemplo de esto se halle en la figura del indio, alternativamente presentado con las connotaciones negativas del «salvaje» cruel y con los rasgos propios del «buen salvaje» descrito por Rousseau. Pues bien, son los escritores indios de hoy quienes están destruyendo tales imágenes simplificadoras de la realidad y se están presentando a sí mismos como los seres humanos que son ${ }^{13}$.

En los años 70, la producción de los nativos, que languidecía desde la Primera Guerra Mundial, empezo a cobrar auge dentro del panorama literario canadiense. De manera especialmente notable han irrumpido las mujeres, indias y mestizas, cuyas obras se basan generalmente sobre la vida actual en las reservas y en los centros urbanos. A menudo, ellas emplean elementos derivados de sus tradiciones orales, habitualmente persiguiendo el fin didáctico que siempre ha tenido gran relevancia en el arte nativo. Por ejemplo, en «This Is a Story» Jeannette C. Armstrong utiliza la legendaria figura de Kyoti -más conocido entre nosotros bajo el nombre de Coyote y bajo otras denominaciones en las diferentes lenguas indias - para expresar la esperanza suscitada por él en todo un pueblo hambriento porque ya no consigue pescar salmones ${ }^{14}$. En el relato se funde el mito con la angustiosa realidad de unas poblaciones cuya supervivencia peligra ante la contaminación de los ríos, la excesiva tala de árboles y otros agentes de los desastres ecológicos. Curiosamente, en Canadá ha sido la literatura de los nativos la primera en reflejar la inquietud por la conservación del medio ambiente, un tema que ahora obsesiona a tantos otros escritores del mundo entero ${ }^{15}$.

13 Sobre el tratamiento de los indios en el teatro norteamericano, E.H. Jones observa: «they were characterized in a few stereotypical ways rather than as individuals with distinct personalities». EUGENE H. JONES, Native Americans as Shown on the Stage 1753-1916, Metuchen (N.J.) \& London, The Scarecrow Press, 1988, p. 164.

14 Jeannette C. Armstrong, «This Is a Story», repr. en Thomas KIng (ed.), All My Relations. An Anthology of Contemporary Canadian Native Fiction, McClelland \& Stewart, 1990, pp. 129-35.

15 «Perhaps more than non-natives, Indians have long spoken against pollution and the destruction of the environment, and advocated the conservation of natural resources - for they have always believed in ccological interdependence: in the symbolic relationship of nature with the rest of creation». Penny Petrone, Native Literature in Canada. From the Oral Tradition to the Present, Toronto, Oxford University Press, 1990, p. 180. 
Jeannette C. Armstrong, además de ser conocida por su obra poética, alcanz6 el éxito con su novela Slash, cuyo protagonista es un adolescente que tras haber vivido felizmente su infancia en una reserva india- experimenta el típico «choque cultural» cuando cierran su escuela rural y se ve obligado a desplazarse a la ciudad para estudiar en una escuela integrada ${ }^{16}$. El joven Tommy Kelasket - también conocido por el apodo de Slash- participa como militante en las actividades de protesta violenta organizadas por el movimiento indio en Estados Unidos y Canadá durante los años 60 hasta que, al fin, vuelve a su reserva y comprende que allí se hallaba desde un principio la respuesta a todos sus interrogantes.

Otra novela enmarcada en el mismo período, concretamente entre 1962 y 1968, es Honour the Sun de Ruby Slipperjack. La narradora es una niña de diez años, cuya existencia transcurre plácidamente en una reserva hasta que, al cumplir los trece, ve cómo su madre sucumbe al alcohol y toda su comunidad se desintegra por el alcoholismo y la violencia. Sin lamentaciones ni comentarios moralizantes, la pequeña cuenta los acontecimientos con absoluta simplicidad. Interna en un colegio de la ciudad, conoce unas formas de vida diferentes de la suya. Con dieciséis años vuelve a la reserva y, a pesar de la destrucción que allí encuentra, se siente reconfortada por las enseñanzas de su madre.

El alcoholismo es uno de los temas recurrentes en la literatura nativa y mestiza contemporánea, pues se perfila como el factor más destructivo para los grupos marginales en la actualidad. Beatrice Culleton es una escritora mestiza que aborda tal cuestión en su primera novela, In Search of April Raintree $^{17}$. Trata de dos niñas mestizas que, al ser entregadas en adopción a dos familias diferentes por causa del alcoholismo de sus padres, evolucionan de manera opuesta. April, de apariencia blanca, se avergüenza de su origen mestizo y trata de integrarse plenamente en la sociedad blanca, primero estudiando y después casándose con un rico empresario de Toronto. Por el contrario, Cheryl, de rasgos físicos indios, analiza la historia de su pueblo y de manera muy idealista se rebela contra la cultura dominante en Canadá. Ahora bien, Cheryl se desilusiona pronto y entonces comienza la anulación de su personalidad por el alcoholismo y la prostitución. Al final, Cheryl se suicida lanzándose desde el mismo puente en el que su madre encontró la muerte. El suicidio de Cheryl induce a April a la reflexión, tras una fuerte crisis motivada por

16 Jeannette C. Armstrong, Slash, Penticton (B.C.), Theytus Books, 1985, 1988 (rev. ed.).

17 Beatrice Culleton, In Search of April Raintree, Winnipeg, Pemmican Publications, 1983. 
el fracaso de su matrimonio y una brutal violación. April acepta su condición de mestiza, se hace cargo del hijo de su hermana y se dispone a reconstruir su propia vida.

Ninguna de las dos protagonistas de In Search of April Raintree ha disfrutado realmente de los aspectos positivos de su propia cultura. Todo lo contrario sucede en la autobiografía de Maria Campbell, Halfbreed, en la que la narradora consigue sobrellevar los problemas derivados de la pobreza de su familia y el alcoholismo del padre, gracias al apoyo afectivo y espiritual de su abuela india $^{18}$. La situación cambia cuando fallece la madre; la abuela ha de abandonar la familia y Campbell debe cuidar a sus seis hermanos. Casada a los quince años con un blanco, al fracasar su matrimonio, se ve inmersa en el mundo del alcohol, las drogas y la prostitución hasta la edad de treinta y tres años. Entonces reacciona e inicia una nueva vida, no exenta de dificultades, alentada por el recuerdo de las enseñanzas de su querida abuela Cheechum e integrada de nuevo en su entorno mestizo.

Maria Campbell, a lo largo de su autobiografía, expresa el orgullo de ser mestiza e insiste en las diferencias que hay entre los indios puros y los mestizos. Según ella, mientras los primeros suelen ser pasivos y silenciosos, los últimos son expresivos y temperamentales. Frente a los indios, protegidos en reservas y apegados a sus tierras, los mestizos son los absolutamente desposeídos, por no tener ni siquiera un territorio que reclamar. Idéntico orgullo por la herencia mestiza manifiesta Jovette Marchessault, feminista radical, autora de obras de teatro y novelas redactadas en francés. Comme une Enfant de la terre y La Mère des herbes, traducidas al inglés bajo los títulos de Like a Child of the Earth y Mother of the Grass, constituyen la primera y segunda parte de una trilogía en la que se explora la infancia feliz de una niña que al llegar a la adolescencia sufre una serie de dolorosas experiencias, finalmente superadas gracias al apoyo de su abuela ${ }^{19}$. Ya desde pequeña, la protagonista percibe con miedo el espacio de los blancos, como una zona prohibida, y desde una cierta distancia observa el comportamiento de las familias católicas de origen francés. Entonces llega a la conclusión de que esos padres coartan a sus hijos restringiendo su libertad y destruyendo su espontaneidad con una serie de reglas emanadas del temor a la vida.

Las experiencias de escritoras inuits, tales como Alice French y Minnie Aodla Freeman, relatadas a través de My Name Is Masak y Life Among the Qallunaat, en

18 Marua CAMPBELL, Halfbreed, Toronto, McClelland \& Stewart, 1973.

19 JovetTe MARCheSSAult, Like a Child of the Earth, Vancouver, Talonbooks, 1988. Mother of the Grass, Vancouver, Talonbooks, 1989. 
poco difieren de las expuestas por las indias y mestizas anteriormente citadas ${ }^{20}$. Las imágenes idilicas de la vida en la reserva contrastan con la tristeza y la soledad que las niñas sienten en el colegio durante su adolescencia, preludio de mayores sufrimientos en un entorno dominado por la cultura de los blancos.

Si comparamos los argumentos de las obras mencionadas, observaremos los principales rasgos comunes que presentan: abundancia de elementos autobiográficos, ruptura con la familia como fuente de los males ulteriores, desastrosas consecuencias del contacto con la cultura dominante, apoyo moral proporcionado por figuras femeninas (en especial, las abuelas) y decisión final de volver a las raíces para reconstruir una vida casi deshecha. Ahora bien, los argumentos pueden dar una idea distorsionada de las obras en su conjunto, pues sitúan en un primer plano lo que ellas tienen de melodramático. Sin embargo, pueden pasar desapercibidas las cualidades fundamentales de un lenguaje unas veces sencillo y directo, pero otras lleno de metáforas, símbolos y alegorías, generalmente derivados de la cultura tradicional.

Como hemos podido comprobar, muchas obras giran en torno a la herencia mixta de los mestizos y a los inevitables conflictos que sufren las personas inmersas alternativa o simultáneamente en culturas divergentes. Por lo general, los contactos con la cultura mayoritaria se perciben como fuente constante de frustración y dolor. Hay una voluntad permanente de resaltar los factores positivos de las propias raíces y los negativos del desarraigo. También aparece la solidaridad con otros grupos marginados, reforzando así la oposición frente al adversario común, aunque ocasionalmente hay muestras de ciertas tensiones entre quienes soportan una misma suerte.

Como ejemplo de apoyo entre los marginados, podríamos citar «Turtle Gal», el relato de Beth Brant, en el que una niña india (cuya madre alcohólica acaba de morir) solicita ayuda a un vecino, un anciano negro doblemente alienado por su raza y por su condición de homosexual ${ }^{21}$. El viejo James adopta a SueLinn como si de su propia nieta se tratara, desafiando a las autoridades que pudieran negarle el derecho de custodia. Además, la niña recibe el apoyo psicológico de una maestra negra, físicamente muy atractiva, que se presenta ante sus alumnos orgullosa de su origen africano.

20 Minnie Aodla Freeman, Life Among the Qallunaat, Edmonton, Hurtig Publishers, 1978. "Qallunaat» (o las variantes de «Kadluna», «Qallunnaq» $y$ «Qullunaaq», entre otras) significa literalmente *gentes con las cejas pobladas y es el término con el que los inuits designan a las personas que no pertenecen a su raza. Sobre la literatura inuit en inglés, véase: PENNY PETrone (ed.), Northern Voices: Inuit Writing in English, Toronto, University of Toronto Press, 1988.

21 Beth Brant, «Turtle Gal», repr. en Thomas King (ed.), All My Relations. An Anthology of Contemporary Canadian Native Fiction, McClelland \& Stewart, 1990, pp. 107-22. 
Por el contrario, la escuela como amenaza para la identidad de la familia inmigrante aparece en «The Other Family», un relato de Himani Bannerji, escritora nacida en Bangladesh que desde 1969 reside en Canada ${ }^{22}$. El argumento es simple: una niña vuelve de la escuela a casa contenta por haber dibujado a su familia. La madre siente una mezcla de rabia y tristeza al comprobar que su hija ha pintado una familia blanca cuando, en realidad, ellos tienen los rasgos propios de las gentes de la India. En definitiva, la madre se considera rechazada por su propia hija y se lamenta de haberla llevado a un país en el que sólo la raza blanca goza de prestigio. La niña guarda silencio y, por la noche, se contempla en un espejo. Al día siguiente, de nuevo en la escuela, junto a las figuras rubias y de ojos azules, dibuja a su propia familia. Es «la otra familia».

Himani Bannerji, autora de dos libros de poesía que algunos han tachado de «propaganda política» ${ }^{23}$, es muy consciente del peligro que para las minorias étnicas representa el potenciar un multiculturalismo reducido a ciertos festivales folclóricos subvencionados, capaces de generar la falsa ilusión de que se está valorando a las minorías, cuando en realidad no se incorpora de ellas nada sustancial para la vida cotidiana, sino que se las está utilizando como un mero espectáculo.

A muchas escritoras canadienses no les satisface la artificialidad que radica en el hecho de exhibir trajes típicos y recordar la gastronomía de los países de origen durante unos determinados días del año, mientras que el resto del tiempo se desprecia y margina a las minorías. Abogan por una nueva identidad, diferente de la que hubieran tenido si hubiesen permanecido en la India, la China o el Caribe, pero diferente también de la que les ofrece la cultura mayoritaria de Canadá. Se trata, pues, de desarrollar unas nuevas formas de cultura que Bannerji denomina «sintética» ${ }^{24}$. En sus obras escuchamos tanto las voces que hablan en nombre de una comunidad como las que se dirigen a esa misma comunidad, porque para ellas el acto de escribir no es simplemente una manera de expresarse y afirmarse como seres individuales y miembros de su etnia, sino también la forma de configurarla y orientarla en el mismo sentido.

22 Himan BANNERI, «The Other Family», repr. en Linda Hutcheon \& MARION Richmond (eds.), Other Solitudes. Canadian Multicultural Fictions, Toronto, Oxford University Press, 1990, pp. 141-5.

23 Himani Bannerr, A Separate Sky, Toronto, Domestic Bliss, 1982 y Doing Time, Toronto, Sister Vision, 1986.

24 Entrevista de Himani Bannerji con Arun Prabha Mukherjee, en LnNDA HuTChEON \& MARION RICHMOND (eds.), Other Solitudes. Canadian Multicultural Fictions, Toronto, Oxford University Press, 1990, p. 149. 
Como ejemplo de novelista que se dirige a la mayoría blanca, podemos citar a Maria Campbell, impulsada por la voluntad de explicar a los blancos qué significa ser una mujer mestiza. En cambio, Beatrice Culleton escribió para sí misma In Search of April Raintree (obra dedicada a sus dos hermanas, que se suicidaron como Cheryl y su madre en la novela). El libro significó una especie de catarsis para una autora que hasta entonces no había conseguido aceptar o comprender el alcoholismo de su propia madre. Para Elizabeth Cook-Lynn (india de raíces Crow, Creek y Sioux), el deseo de escribir surgió del sentimiento de privación que - parafraseando sus propias palabras - en un principio provoca silencio, después desconfianza, más tarde rabia y, por último, se convierte en un acto de desafío originado por la necesidad de sobrevivir. «Soy yo. Existo. Escribo" ${ }^{25}$.

Los aspectos autobiográficos prevalecen en una literatura testimonial y de protesta, obsesivamente preocupada por denunciar las injusticias del sistema. A menudo se rechaza explícitamente el principio de «el arte por el arte». Existe un afán didáctico, un empeño por demostrar la autenticidad de las situaciones que a veces impulsa a reproducir documentos dentro de los mismos textos literarios, o al principio, como citas breves, o bien como apéndices más extensos al final de las obras. Por lo general, estas autoras intentan articular los sentimientos —en ocasiones contradictorios- de una generación que está sufriendo una fuerte crisis de identidad al esforzarse por encontrar nuevas formas de vida que combinen el progreso con la tradición. Estos intentos de armonización se reflejan en unas obras literarias a través de las cuales queda patente el deseo de mantener la herencia cultural incorporando en los relatos algunos elementos de las antiguas leyendas $y$, al mismo tiempo, se perciben las influencias externas recibidas dentro de un mundo en el que la comunicación cada vez cobra mayor importancia y alcanza lugares más lejanos.

El ámbito familiar suele ser el único refugio de unos personajes que se sienten permanentemente discriminados o incluso agredidos. La figura de la madre, tan cuestionada por las escritoras actuales pertenecientes a la mayoría sociocultural, queda realzada por las escritoras de las minorías. Mientras que

25 «Wanting to write comes out of that deprivation, though, for we eventually have to ask, what happens to a reasonably intelligent child who sees himself or herself excluded from a world which is created and recreated with the obvious intent to declare him or her persona non grata? Silence is the first reaction. Then there comes the development of a mistrust of that world. And, eventually, anger. That anger is what started me writing. Writing for me, then, is an act of defiance out of the need to survive. I am me. I exist... I write». Palabras de Elizabeth Cook-Lynn transcritas en Brian SWANn \& ARnold Krupat (eds.), I Tell You Now: Autobiographical Essays by Native American Writers, Lincoln, University of Nebraska Press, 1987. 
los conflictos con los maridos son igualmente habituales en ambas producciones literarias, los intensos lazos afectivos que unen a las abuelas, madres e hijas de las etnias minoritarias contrastan con el individualismo, la frialdad o la confrontación abierta que caracterizan las relaciones entre las mujeres de distintas generaciones dentro del grupo social mayoritario.

Además de las coincidencias, un examen detallado de estas nuevas obras revela unas tendencias antagónicas que suscitan nuestro interés. El optimismo coexiste paralelamente con el pesimismo, las celebraciones festivas se alternan con las estrategias de resistencia y supervivencia, las escenas idílicas se combinan con otras lúgubres; las inclinaciones hacia la evasión, mediante el desarrollo de la fantasía, se contrarrestan con las reacciones combativas propias de la militancia política. Todas desean hacer oír sus propias voces narrativas y se rebelan contra el hecho de ser consideradas como meros objetos de curiosidad intelectual. Saben que de ellas se espera «autenticidad" y son conscientes del peligro que supone el verse obligadas a satisfacer siempre las expectativas de sus lectores. Por eso algunas se plantean el reto de romper con los estereotipos: evitan conscientemente los aspectos pintorescos, experimentan con un talante innovador y abordan cuestiones que nadie pensaba fueran a tratar.

Si desde un comienzo tales escritoras utilizaron la ironía como instrumento subversivo frente a sus opresores, en la actualidad demuestran su creciente poder de afirmación dirigiendo este arma también hacia aquellas facetas de su propia cultura que, a su juicio, merecen ser enfocadas con humor. Eso es algo que sólo ellas pueden y deben hacer, explorando así nuevos territorios de la imaginación, atravesando los límites que originariamente restringieron sus impulsos creativos a unos determinados temas y tonos que ahora ellas prefieren ampliar. 